\title{
Passive smoking and respiratory symptoms in the FinEsS Study
}

\author{
M.L. Larsson*, H-M. Loit\#, M. Meren\#, J. Põlluste\#, A. Magnusson`, K. Larsson ${ }^{+}$, B. Lundbäck ${ }^{+, \S}$
}

Passive smoking and respiratory symptoms in the FinEsS Study. M.L. Larsson, H-M. Loit, M. Meren, J. Põlluste, A. Magnusson, K. Larsson, B. Lundbäck. C ERS Journals Ltd 2003.

ABSTRACT: The aim of the present study was to examine the relationship between reported environmental tobacco smoke (ETS) exposure and respiratory symptoms.

In 1996, a postal questionnaire was randomly distributed in three areas of Estonia to a population-based sample, of which 4,995 females and 1,822 males had never smoked. The main outcome measures were current respiratory symptoms and the amount of reported ETS exposure outside the home.

ETS exposure at home was more common in females $(31 \%$ versus $19 \%)$, while exposure outside of the home was more common in males $(53 \%$ versus $7 \%)$. Females reported more symptoms from tobacco smoke than males $(37.7 \%$ versus $21.6 \%)$. If ETS exposure outside of the home exceeded $5 \mathrm{~h}$ daily, the risk for wheeze (odds ratio (OR) 2.67, 95\% confidence interval (CI) 1.98-3.61) and physician-diagnosed asthma (OR $1.79,1.02-3.16)$ were increased. ETS exposure outside of the home was shown to be strongly related to almost all respiratory symptoms in a dose/response manner. ETS exposure at home did not show significantly elevated ORs for any respiratory symptoms.

This study shows that females seem to be more troubled by environmental smoke exposure than males and provides further evidence of the serious health hazards associated with environmental smoke exposure. Indeed, the findings of this study support a ban on smoking in the workplace and public areas.

Eur Respir J 2003; 21: 672-676.

\begin{abstract}
*Dept of Lung Medicine and "The Research Unit, Örebro University Hospital, Örebro, ${ }^{+}$The Institute of Environmental Medicine, Karolinska Institutet, Stockholm, and ${ }^{\S}$ The OLIN studies, Dept of Medicine, Sunderby Central Hospital of Norrbotten, Luleå, Sweden. ${ }^{\#}$ Dept of Pulmonology, Institute of Experimental and Clinical Medicine, Tallinn, Estonia.
\end{abstract}

Correspondence: M.L. Larsson, Dept of Lung Medicine, Örebro University Hospital, SE-701 85 Örebro, Sweden

Fax: 4619186526

E-mail: matz.larsson@orebroll.se

Keywords: Asthma, epidemiology, passive smoking, respiratory symptoms

Received: April 252002

Accepted after revision: November 282002

This study was supported by grants from the Estonian Science Foundation, The National Health Institute, The Heart and Lung Foundation, and The Research Committee of Örebro County Council, Sweden.
The 1992 US Environmental Protection Agency (EPA) review [1] on passive smoking confirmed that exposure to environmental tobacco smoke (ETS), i.e passive smoking, can cause respiratory illness in children. There is also increasing evidence of ETS causing respiratory illness in adults [2-11]. The US EPA review also includes reports on a relationship between ETS, respiratory symptoms and sickness in adults [1]. WHITE et al. [7] showed that workplace ETS is more strongly related to respiratory symptoms than household exposure, a finding which has also been shown in other studies [8,9]. There are almost 4,000 chemical agents in ETS, including nicotine, carbon monoxide, benzene, formaldehyde, and acrolein, all of which are emitted from a burning cigarette and could cause respiratory symptoms [12]. For many subjects with asthma, acute exposure to ETS is associated with respiratory symptoms [13] and ETS exposure has been reported to increase bronchial reactivity to histamine in asthmatics [14]. LEUENBERGER et al. [8] reported on the increasing risk and dose relationship for respiratory symptoms related to total ETS exposure. In November 1999 the US National Cancer Institute published an extensive report [10] on health risks of ETS exposure. In the report, no definite conclusion on the association between ETS and chronic respiratory symptoms in adults was reached. Since this report, a dose relationship between exposure to ETS at work and respiratory symptoms in never-smokers, an important criterion for causal association, has been shown by others $[9,11]$. In the study by LAM et al. [11], performed on police officers with a small proportion of females, the association was clear among males but less clear among females. Studies concerning ETS and chronic respiratory symptoms in adults have mainly been performed on selected groups or with pooled data from many different countrys [9].

This study was conducted as a result of conflicting results in previous studies, lack of data from population-based random samples, lack of data from Eastern Europe and the scarcity of knowledge concerning females. The study's main aim was to examine the respiratory effects of ETS exposure in a random sample of adult never-smokers from a general population. A further aim was to study whether the respiratory effects of ETS exposure are different in males and females.

\section{Materials and methods}

\section{Participants and survey}

This study was a part of the epidemiological studies performed in Finland, Estonia, and Sweden (FinEsS) on the prevalence of and risk factors for asthma, chronic bronchitis, type-1 allergy, and respiratory symptoms. The present investigation was based on the Estonian part of the study, which was approved by the Tallinn Medical Research Ethics Committee.

\section{Study population}

A random sample of 24,307 individuals stratified on a 10-yr age band and sex were selected from the populations of Tallinn (442,679 inhabitants), Narva (79,094 inhabitants) and Saaremaa (40,822 inhabitants). The Estonian State Computing Centre population register was used to identify subjects. 
This register is updated on a fortnightly basis. Smokers, former smokers, and subjects reporting "I don't leave home" were excluded. Prevalence rates of respiratory symptoms in this population have recently been reported [15].

\section{Questionnaire}

The questionnaire [16] was developed from a revised version of The British Medical Research Council questionnaire [17] and had been previously validated and used in several Scandinavian studies. The postal questionnaires were sent to the study sample with an explanatory note, an envelope, and a stamp during November 1995. In a case in which there was no response, two reminders were sent to the subject. In Estonia, two versions of the questionnaire were used, a Russian and an Estonian version. The Russian version was mailed to subjects with Russian names and the Estonian version to subjects with Estonian names. In cases in which the subject's language was uncertain, both versions were sent. The questionnaire included questions about respiratory symptoms and diseases, for example recurrent wheeze, attacks of shortness of breath, long-standing cough, sputum production, asthma, allergic rhinitis, chronic bronchitis and symptoms in special circumstances with varying exposures. The questionnaire also included questions about smoking habits, occupation, and family history of the above mentioned diseases. Two questions concerning exposure to ETS at home and outside the home were added in the Estonian study, exclusively, and were as follows. 1) "Does somebody of your family member smoke at home in living rooms?" This question was answered with either "yes" or "no/don't know", as were all questions concerning symptoms. 2) "How many hours per day do you spend in smoky rooms outside your home?" The reply had to be one of the following alternatives: ">5 h·day ${ }^{-1}$ ", "1-5 h·day ${ }^{-1 ",}$ " $<1 \mathrm{~h} \cdot$ day $^{-1 "}$ ", "nearly never", "I don't leave home".

\section{Definitions}

Exposure to ETS at home was defined as a positive answer to the first ETS question seen above. Exposure to ETS outside home was estimated by the answer to the second ETS question seen above. A never-smoker was defined as someone giving a negative reply ("no/don't know") to the two following questions: 1) "Do you smoke? (smokers also include those who smoke a few cigarettes or pipe fills a week, and those who have stopped during the last 12 months)"; and 2) "Have you been a smoker but have stopped smoking $>1$ yr ago?"

The following definitions of the dependent variables were used for respiratory symptoms or conditions. Long-standing cough: having had a long-standing cough during the last few years. Increased sputum production: often having phlegm when coughing or having difficulties in bringing up phlegm. Chronic productive cough: bringing up phlegm when coughing on most days during periods of $\geqslant 3$ months during at least 2 successive yrs. Wheeze: wheezing, whistling or a noisy sound in the chest when breathing. Wheezing during the last 12 months or having had wheezing or whistling in the chest at any time during the last 12 months. Woken with chest tightness or having woken with chest tightness at any time in the last 12 months. Dyspnoea grade 2: getting short of breath or having to walk more slowly when walking with other people of the same age on level ground at a normal pace. Physician-diagnosed chronic bronchitis: having been diagnosed as having chronic bronchitis or emphysema by a physician. Physician-diagnosed asthma: having been diagnosed as having asthma by a physician.

\section{Lower airway irritant}

The questionnaire also included the following nine questions concerning exposures and/or circumstances with the potential to cause lower airway irritation: "Do you become breathless or wheeze, or do you have attacks of cough when exposed to 1) exercise, 2) cold air, 3) exercise in cold air, 4) dust, 5) tobacco smoke, 6) car exhaust fumes, 7) strong smells, e.g. perfume, spices, printers ink, 8) pollen from plants and/or trees, or 9) pets?" If a positive response was given, the factor and/or circumstance were defined as a lower airway irritant. Odds ratios (ORs) for giving a positive response to questions concerning various lower airway irritants were calculated in relation to reported ETS-exposure duration. This was performed in an identical manner to the calculations of OR for respiratory symptoms (see Data analysis).

\section{Data analysis}

The analyses were based only on the participants who had never smoked. When estimating the effects of ETS exposure outside the home on respiratory symptoms, multiple logistic regression was used to calculate OR values with $95 \%$ confidence intervals (CIs), adjusted for age, sex, heredity for asthma and/or bronchitis/emphysema, community and ETS exposure at home. Males and females were analysed together, but an interaction between the subject factor sex and the within factor ETS exposure outside home was tested with a likelihood ratio test [18]. This was obtained as minus twice the difference between log-likelihood for the models with and without the interaction term. Dose/response was also analysed in the same way with a likelihood ratio test, by comparing a linear ETS exposure effect coded from 1 to 4 , where 1 was "nearly never" and 4 was ">5 h".

\section{Results}

From the 24,307 subjects eligible to join the survey a total of $17,725(77.6 \%)$ completed the questionnaire. Amongst the respondents, 8,022 subjects were never-smokers and from these 1,205 were excluded because of missing entries for ETS exposure. In total 6,817 never-smokers were included in the survey, 4,995 of which were female.

The demographical characteristics and exposure to ETS at home or work are shown in table 1. Exposure at home was more common in females $(31 \%)$ than in males $(19 \%)$. In contrast, exposure outside the home was more common in males $(53 \%)$ than in females $(37 \%)$ and $23 \%$ of the males reported $\geqslant 1 \mathrm{~h}$ of ETS exposure outside of the home compared to $16 \%$ of females.

Exposure times to ETS outside of the home showed a significant dose/response relationship with all respiratory symptoms and conditions (table 2), except for physiciandiagnosed asthma, where only a slight increase was observed. The reported duration of ETS exposure was associated with positive responses for all types of lower airway irritants (table 3).

There were no significant interactions by sex on the dose/ response for ETS exposure duration, respiratory symptoms, or the lower airway irritants, except for tobacco smoke which showed a significant interaction by $\operatorname{sex}(\mathrm{p}=0.02)$. The ORs gave positive responses meaning tobacco-smoke was reported as a lower airway irritant; for example, when reporting tobacco smoke to be a lower airway irritant, they were 1.50 (CI 1.28-1.77), 1.96 (1.57-2.45) and 1.53 (1.18-1.97) for low, medium and high exposures, respectively, in females, and $1.12(0.83-1.52), 1.11(0.77-1.59)$ and $1.77(1.11-2.80)$ for low, 
Table 1. - Demographical characteristics and pattern of environmental tobacco smoke (ETS) exposure in the never-smoking population

\begin{tabular}{lcr}
\hline & Males & Females \\
\hline $\begin{array}{l}\text { Subjects n } \\
\text { Age yr }\end{array}$ & 1822 & 4995 \\
$15-24$ & $628(34.5)$ & $1015(20.3)$ \\
$25-34$ & $331(18.2)$ & $845(16.9)$ \\
$35-44$ & $289(15.9)$ & $983(19.7)$ \\
$45-54$ & $270(14.8)$ & $1046(20.9)$ \\
$55-64$ & $304(16.7)$ & $1106(22.1)$ \\
ETS exposure at home & & \\
$\quad$ No & $1472(80.8)$ & $3431(68.7)$ \\
$\quad$ Yes & $350(19.2)$ & $1564(31.3)$ \\
Daily ETS exposure time & & \\
outside of the home & $864(47.4)$ & $3148(63.0)$ \\
Nearly never & $545(29.9)$ & $1050(21.0)$ \\
$<1 \mathrm{~h}$ & $295(16.2)$ & $323(9.5)$ \\
1-5 h & $118(6.5)$ & \\
$>5 \mathrm{~h}$ &
\end{tabular}

Data presented as n (\%) unless otherwise stated.

medium and high exposures, respectively, in males (exposures are as defined in table 3 ).

All respiratory symptoms and conditions were more common in females than in males, except physician-diagnosed asthma, where the OR for females was $0.93(0.62-1.39)$ (table 4). The female predominance was most clearly observed in dyspnoea grade 2 (OR 2.88 (2.13-3.90)), followed by increased sputum production (OR 1.67 (1.45-1.93)) and least pronounced physician-diagnosed chronic bronchitis (OR $1.29(1.04-1.60))$.

Tobacco smoke was the most commonly reported lower airway irritant, followed by dust, amongst both males and females together and females only (fig. 1). Dust was the most commonly reported lower airway irritant in males, followed by tobacco smoke. Females more frequently gave positive responses to all questions concerning lower airway irritants.

ETS exposure at home showed no significant increase in ORs for respiratory symptoms. If the group exposed to ETS at home was considered a reference category (OR 1.0), the OR for nonexposed was $1.03(0.89-1.18)$ for long-standing cough, $1.13(0.92-1.38)$ for wheeze, $1.05(0.90-1.23)$ for wheezing in the last 12 months, and $1.32(1.12-1.56)$ for being woken up during the night with chest tightness.

\section{Discussion}

This study shows a clear association and a strong dose/ response relationship between ETS exposure outside the home and respiratory symptoms. This study also suggests that ETS exposures outside the domestic area brought about more serious effects than ETS exposures at home. The study found

Table 2. - Adjusted odds ratios (ORs) for different respiratory symptoms by daily exposure time to environmental tobacco smoke (ETS) outside of the home

Symptoms
ETS outside home

\begin{tabular}{cccr}
\multicolumn{4}{c}{ ETS outside home } \\
\hline$<1 \mathrm{~h}$ & $1-5 \mathrm{~h}$ & $>5 \mathrm{~h}$ & p-value* \\
\hline $1.25(1.07-1.45)$ & $1.40(1.16-1.71)$ & $1.61(1.27-2.03)$ & $<0.001$ \\
$1.32(1.14-1.52)$ & $1.56(1.29-1.87)$ & $1.52(1.21-1.91)$ & $<0.001$ \\
$1.32(1.01-1.72)$ & $2.00(1.47-2.74)$ & $1.81(1.25-2.62)$ & $<0.001$ \\
$1.25(0.99-1.59)$ & $2.12(1.61-2.78)$ & $2.67(1.98-3.61)$ & $<0.001$ \\
$1.15(0.97-1.37)$ & $1.41(1.13-1.76)$ & $1.85(1.43-2.39)$ & $<0.001$ \\
$1.11(0.92-1.35)$ & $1.37(1.08-1.73)$ & $1.64(1.25-2.15)$ & $<0.001$ \\
$1.02(0.80-1,30)$ & $1.75(1.32-2.31)$ & $1.65(1.20-2.27)$ & $<0.001$ \\
$0.85(0.54-1.34)$ & $1.21(0.71-2.07)$ & $1.79(1.02-3.16)$ & 0.098 \\
$1.24(1.01-1.53)$ & $1.16(0.88-1.53)$ & $1.54(1.13-3.00)$ & 0.006 \\
\hline
\end{tabular}

Long-standing cough

Increased sputum production

Chronic productive cough

Wheeze

Wheezing in last 12 months

Woken up with tightness in chest

Dyspnoea grade 2

Physician-diagnosed asthma

Physician-diagnosed chronic bronchitis or emphysema

All data presented as OR (95\% confidence interval) unless otherwise stated. The ORs were adjusted for age, sex, heredity for asthma or bronchitis/emphysema, community, and ETS exposure at home and were calculated using subjects reporting almost no ETS exposure outside of the home as a reference category; *: linear dose/response relationship.

Table 3. - Adjusted odds ratios (ORs) for reporting problems from different lower airway irritators by daily exposure time to environmental tobacco smoke (ETS) outside of the home

\begin{tabular}{|c|c|c|c|c|}
\hline \multirow{2}{*}{$\begin{array}{l}\text { Lower airway irritating } \\
\text { factors/circumstances }\end{array}$} & \multicolumn{4}{|c|}{ ETS outside home } \\
\hline & $<1 \mathrm{~h}$ & $1-5 \mathrm{~h}$ & $>5 \mathrm{~h}$ & p-value* \\
\hline Exercise & $1.06(0.86-1.31)$ & $1.34(1.04-1.75)$ & $1.25(0.90-1.74)$ & 0.031 \\
\hline Cold & $1.22(1.03-1.46)$ & $1.22(0.97-1.54)$ & $1.57(1.21-2.05)$ & $<0.001$ \\
\hline Exercise in cold air & $1.15(0.97-1.36)$ & $1.23(0.99-1.53)$ & $1.68(1.31-2.17)$ & $<0.001$ \\
\hline Dust & $1.28(1.11-1.48)$ & $1.31(1.09-1.58)$ & $1.57(1.25-1.97)$ & $<0.001$ \\
\hline Tobacco smoke & $1.39(1.21-1.60)$ & $1.63(1.35-1.96)$ & $1.58(1.26-1.98)$ & $<0.001$ \\
\hline Car exhaust fumes & $1.35(1.16-1.58)$ & $1.65(1.35-2.02)$ & $1.38(1.08-1.76)$ & $<0.001$ \\
\hline Perfume, etc. & $1.38(1.17-1.63)$ & $1.59(1.29-1.98)$ & $1.42(1.10-1.84)$ & $<0.001$ \\
\hline Pollen & $1.32(1.00-1.75)$ & $1.17(0.81-1.70)$ & $1.67(1.13-2.46)$ & $<0.012$ \\
\hline Pets & $1.30(0.92-1.84)$ & $1.67(1.11-2.50)$ & $1.99(1.27-3.11)$ & $<0.001$ \\
\hline
\end{tabular}

All data are presented as OR (95\% confidence interval) unless otherwise stated. The ORs were adjusted for age, sex, heredity for asthma or bronchitis/emphysema, community, and ETS exposure at home and were calculated using subjects reporting almost no ETS exposure outside of the home as reference category; *: linear dose/response relationship. 
Table 4. - Odds ratios (ORs) for respiratory symptoms by sex Symptoms Females

Long-standing cough

Increased sputum production

Chronic productive cough

Wheeze

Wheezing in last 12 months

Woken up with tightness in chest

Dyspnoea grade 2

Physician-diagnosed asthma

Physician-diagnosed chronic

bronchitis or emphysema

All data are presented as ORs (95\% confidence interval) with males as the reference category and adjusted for age, heredity for asthma or bronchitis/emphysema, community, ETS exposure at home and exposure time to ETS outside the home.

no significant interactions by sex in the dose/response for ETS exposure duration and respiratory symptoms. However, with almost twice as many females as males reporting that tobacco smoke caused breathlessness, wheezing, and attacks of cough, females seem to be more irritated by ETS exposure. Irrespective of ETS exposure, females in general report more respiratory symptoms, suggesting that when exposed to equal amounts of ETS, females will have more symptoms than males.

LAM et al. [11] did not show dose/response relationships between ETS exposure and respiratory symptoms as clearly in females as in males, but the present study did show females to be at least as sensitive as males to ETS exposure. The strengths of the present study are the sample size, the random selection from the general population and the high participation rate. Furthermore, the smoking prevalence in Estonia is high as $\sim 50 \%$ of the males are smokers (data not presented). Almost no restrictions on ETS existed at the time of the study, giving a reasonable number of exposed subjects for calculations. A potential weakness of this study is the lack of validation regarding smoking status and ETS exposures. Smoking status was self-reported by the participants, which increased the risk of smokers being misclassified as nonsmokers. However, a

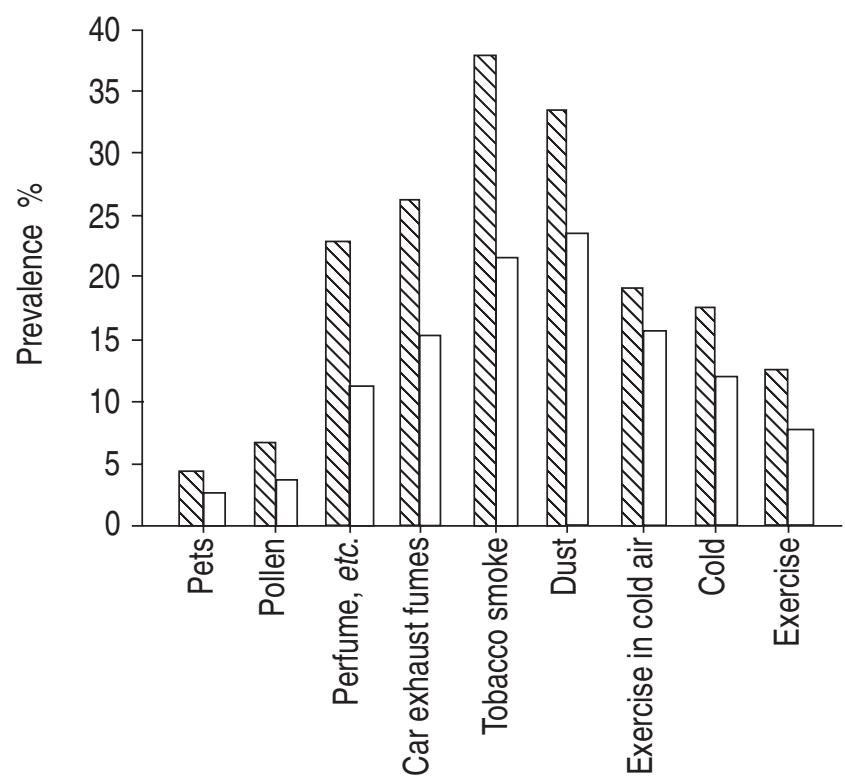

Fig. 1.- Prevalence of positive responses to the questions concerning lower airway irritants in females $(\mathbb{\mathbb { }})$ and males $(\square)$. meta-analysis [19] of the validity of self-reported smoking suggested a high sensitivity (87\%) and specificity (89\%) for self-report. Indeed, RiBOLI et al. [20] estimated that the proportion of females misreporting their active smoking habit was between $1.9-3.4 \%$ in 13 centres from 10 countries. If a misclassification of $3.5 \%$ is assumed, misclassification of smoking status does not explain the excess risks associated with ETS. Thus, possible misclassification cannot explain the strong ETS effects observed in both females and males. However, it is possible that some nonsmokers did not report ETS exposure even if they were exposed and, therefore, could have been misclassified as unexposed. A validation of outcome measures for respiratory symptoms was not performed, but these measures have been tested in several other studies and been found to have a high level of validity [21].

Another potential weakness is that the levels of ETS exposure were not directly measured. However, the selfreported ETS exposure can be accepted as a valid measure in the study as clear dose/response relationships were observed between the reported time with ETS exposure outside the home and most respiratory symptoms. The respondents were anonymous and would have found no advantages, real or expected, to giving falsified reports. The participants reported respiratory symptoms first and ETS exposure later in the questionnaire, which makes it less likely that reported respiratory symptoms would be biased by reported exposure to ETS. Subjects with asthma or chronic obstructive pulmonary disease might be more aware of ETS exposure, owing to an increased bronchial reactivity, and might therefore overestimate the length of exposure, leading to an overestimation of the risk [22]. Alternativley, subjects with airway disorders like asthma might be more likely to avoid ETS and, if successful, will report less exposure, leading to an underestimation of the risk. This perhaps partly explains the lack of association between passive smoking at home and respiratory symptoms, i.e. family members may be more likely to stop or reduce smoking if one of their family members develops respiratory symptoms.

ETS exposure at home slightly increased ORs for some respiratory symptoms, but were not statistically significant. LAM et al. [11] concluded that "stronger effects were observed at work where the risk of ETS exposure was much greater because subjects spent more time among a larger number of smoking co-workers at work than at home". The present study did not separate ETS exposure at work from other sources of ETS exposure outside of the home. It seems reasonable, however, that ETS exposure outside of the home was mainly related to work, since most of the subjects were of working age. Therefore, this study supports the hypothesis that ETS exposures outside the domestic area have more serious effects than ETS exposure at home. A recent study [23] showed that the amount of metabolites in a tobacco smoke-specific carcinogen in urine was six times higher among females exposed to ETS at home than amongst nonexposed females. As studies concerning airway symptoms and ETS exposure imply that ETS exposure in the workplace is more harmful, a study of tobacco smoke-specific carcinogens in urine after ETS exposure at work is urgently required. There is also a lack of epidemiological data concerning workplace ETS exposures and lung cancer [24].

In Estonia the level of awareness about the effects of ETS is currently low and few workplaces have smoking restrictions or have banned smoking. In the present study, $20 \%$ of the subjects were exposed to ETS outside home for $>1 \mathrm{~h} \cdot \mathrm{day}^{-1}$. This level of exposure was associated with a 50\% higher prevalence of symptoms like phlegm, cough and dyspnoea. The present data indirectly supports many studies $[9,25,26]$, indicating that ETS exposure is associated with small deficits in adult lung function. 
Cigarette smoke was the most commonly reported cause of lower airway irritation in the present study and a previous Swedish study [28]. The present authors also found a clear association between ETS exposure outside the home and airway symptoms from a variety of lower airway irritants. Most of these were known, unspecific airway irritants, e.g. cold air and strong-smelling scents. However, some were found to be rather surprising agents, commonly related to immunoglobulin (Ig)E-mediated allergies, e.g. pollen and animals with fur. From the present data it cannot be determined whether ETS exposure just triggers unspecific airway sensitivity or increases the risk of IgE-mediated allergy, which has been shown in active [28] but not passive smokers [9].

The high prevalence of chronic respiratory symptoms clearly represents a major public health problem. Exposure to ETS in society is preventable. Banning smoking in the workplace can significantly and rapidly improve the respiratory health of employees [29] and has also been reported to reduce the number of daily smokers and the number of cigarettes consumed in prevailing smokers. Implementation of stronger legislation in Estonia and all other countries with few regulations against ETS should be of high priority.

In summary, the reported duration of daily passive smoking outside of the home was associated with an increased prevalence of respiratory symptoms and a clear dose/ response. This strongly supports the finding of a causal association.

\footnotetext{
Acknowledgements. The authors would like to thank E. Jönsson for valuable support with the statistical analyses and J. Kiviloog for his encouraging support.
}

\section{References}

1. US Environmental Protection Agency. Respiratory health effects of passive smoking: lung cancer and other disorders. Washington DC, US Environmental Protection Agency, 1992.

2. California Environmental Protection Agency. Health effects of exposure to environmental tobacco smoke. Sacramento, California Environmental Protection Agency, Office of Environmental Health Hazard Assessment, 1997.

3. Jaakkola MS, Jaakkola JJ, Becklake MR, Ernst P. Effect of passive smoking on the development of respiratory symptoms in young adults: an 8-year longitudinal study. $J$ Clin Epidemiol 1996; 49: 581-586.

4. Tredaniel J, Boffetta P, Saracci R, Hirsch A. Exposure to environmental tobacco smoke and adult non-neoplastic respiratory diseases. Eur Respir J 1994; 7: 173-185.

5. Kauffmann F, Dockery DW, Speizer FE, Ferris BG. Respiratory symptoms and lung function in relation to passive smoking: a comparative study of American and French female. Int J Epidemiol 1989; 18: 334-344.

6. Schwartz J, Zeger S. Passive smoking, air pollution, and acute respiratory symptoms in a diary study of student nurses. Am Rev Respir Dis 1990; 141: 62-67.

7. White JR, Froeb HF, Kulik JA. Respiratory illness in nonsmokers chronically exposed to tobacco smoke in the work place. Chest 1991; 100: 39-43.

8. Leuenberger P, Schwartz J, Ackermann-Liebrich U, et al. Passive smoking exposure in adults and chronic respiratory symptoms (SAPALDIA Study). Am J Respir Crit Care Med 1994; 150: 1222-1228.

9. Jansson C, Chinn S, Jarvis D, Zock JP, Torén K, Burney P. Effects of passive smoking on respiratory symptoms, bronchial responsiveness, lung function, and total IgE in the European Community Respiratory Health
Survey: a cross-sectional study. Lancet 2001; 358: 21032109.

10. National Cancer Institute. Health Effects of Exposure to Environmental Tobacco Smoke. Smoking and Tobacco Control Monograph No. 10. http://rex.nci.nih.gov/NCI_ MONOGRAPHS/MONO10/MONO10.HTM.

11. Lam TH, Ho LM, Hedley AJ, et al. Environmental tobacco smoke exposure among police officers in Hong Kong. JAMA 2000; 284: 756-763.

12. Committee on passive smoking, Board of Environmental Studies and Toxicology, National Research Council (NRC). Environmental Tobacco Smoke: Measuring exposures and assessing health effects. Washington DC, National Academy Press, 1986.

13. Shepard RJ, Collins R, Silverman F. "Passive" exposure of asthmatic subjects to cigarette smoke. Environ Res 1979; 20: 392-402.

14. Knight A, Breslin A. Passive cigarette smoking and patients with asthma. Med J Aust 1985; 4: 194-195.

15. Meren M, Jannus-Pruljan L, Loitt H-M, Polluste J, Jönsson E. Asthma, chronic bronchitis and respiratory symptoms among adults in Estonia according to a postal questionnaire. Respir Med 2001; 95: 954-964.

16. Lundbäck B, Nyström L, Rosenhall L, Stjernberg N. Obstructive lung disease in northern Sweden; respiratory symptoms assessed in a postal survey. Eur Respir J 1991; 4: 257-266.

17. Medical Research Council Committee on the aethiology of chronic bronchitis - standardised questionnaires on respiratory symptoms. BMJ 1960; 2: 1665.

18. Hosmer DW, Lemeshow S. Applied Logistic Regression. New York, Wiley, 1989.

19. Patrick DL, Cheadle A, Thompson DC, Diehr P, Koepsell T, Kinne S. The validity of self-reported smoking: a review and meta-analysis. Am J Public Health 1994; 84: 10861093.

20. Riboli E, Preston-Martin S, Saracci R, et al. Exposure of non-smoking women to environmental tobacco smoke: a 10 country collaborative study. Cancer Causes Control 1990; 1: 243-252.

21. Thorén K, Brisman J, Järvholm B. Asthma and asthma-like symptoms in adults assessed by questionnaires. A literature review. CHEST 1993; 104: 600-608.

22. Brand PL, Rijcken B, Schouten JP, Koeter GH, Weiss ST, Postma DS. Perception of airway obstruction in a random population sample. Relationship to airway hyperresponsiveness in the absence of respiratory symptoms. Am Rev Respir Dis 1992; 146: 396-401.

23. Anderson K, Carmella S, Ye M, et al. Metabolites of a tobacco-specific lung carcinogen in nonsmoking women exposed to environmental tobacco smoke. J Natl Cancer Inst 2001; 93: 378-381.

24. Hackshaw AK, Law MR, Wald NJ. The accumulated evidence on lung cancer and environmental tobacco smoke. BMJ 1997; 315: 980-988.

25. Berglund D, Abbey D, Lebowitz M, Knutsen S, McDonnel W. Respiratory symptoms and pulmonary function in an elderly nonsmoking population. Chest 1999; 115: 49-59.

26. Masjedi MR, Kazemi H, Johnson DC. Effects of passive smoking on the pulmonary function of adults. Thorax 1990; 45: 27-31.

27. Larsson M, Frisk M, Hallström J, Kiviloog J, Lundbäck B. Environmental tobacco smoke exposure during childhood is associated with increased prevalence of asthma among adults. Chest 2001; 120: 711-717.

28. Zetterström O, Osterman K, Machado L, Johansson SGO. Another smoking hazard: raised serum IgE-concentration and increased risk of occupational allergy. BMJ 1981; 283: 1215-1217.

29. Eisner MD, Smith AK, Blanc PD. Bartenders' respiratory health after establishment of smoke-free bars and taverns. JAMA 1998; 280: 1947-1949. 